\title{
Analysis of Dissolved Gases by Headspace Sampling Gas Chromatography With Column and Detector Switching. Preliminary Results
}

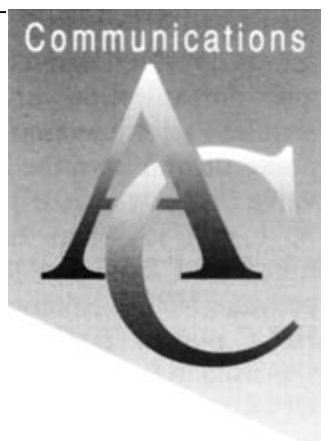

\author{
Pierre-Marie Sarradin and Jean-Claude Caprais \\ IFREMER Centre de Brest, DROIEP, BP 70, 29280 Plouzane, France
}

\begin{abstract}
This preliminary study presents a new method for the determination of dissolved gases in sea-water. After headspace extraction, gaseous compounds are separated by GC on a dual column adsorption system. The individual species are thereafter eluted to three different detectors (thermal conductivity, flame ionization and FPD) using a second switching valve. The analysis is quantitative for methane and carbon dioxide with limits of determination of 0.1 and $50 \mu \mathrm{mol} \mathrm{I}^{-1}$, respectively, and corresponding standard deviations of 4 and $7 \%$, and has been applied to deep sea hydrothermal samples. Further optimization is necessary to allow the quantitative determination of hydrogen sulfide, nitrogen, oxygen and carbon monoxide.
\end{abstract}

Deep sea hydrothermal vents are characterized by the presence of hot fluid sources with unusual chemical compositions, i.e., high temperature, low $\mathrm{pH}$, high sulfide and methane concentrations. Particular ecosystems are associated with these vents. In the absence of light, these are based on chemosynthesis and particularly on the hydrogen sulfide and methane present in the fluid.

The study of the chemical environment of hydrothermal organisms is based on biologically important compounds present in the mixing zone of the hydrothermal hot fluid and the

Table 1 Concentrations of the dissolved gases in sea-water and hydrothermal fluids

$\begin{array}{lll}\text { Gas } & \text { Hydrothermal fluid } & \text { Sea-water } \\ \mathrm{CH}_{4} & 0.001-3.4 \mathrm{mmol} \mathrm{l}^{-1} & 0.4 \mathrm{nmol} \mathrm{I}^{-1} \\ \mathrm{H}_{2} \mathrm{~S} & 0.5-18 \mathrm{mmol} \mathrm{l}^{-1} & \text { trace } \\ \mathrm{CO}_{2} & 2.3-285 \mathrm{mmol} \mathrm{l}^{-1} & 2.4 \mathrm{mmol} \mathrm{l}^{-1}\end{array}$

cold sea-water. Present in the fluid are the dissolved gases $\mathrm{CH}_{4}$, $\mathrm{H}_{2} \mathrm{~S}$ and $\mathrm{CO}_{2}$ (Table 1).

In this study, sampling was carried out using a sampler deployed from the French deep-sea submersible research vessel Nautile. Samples were difficult to obtain and had to be handled with care as other analyses were carried out on the $150 \mathrm{ml}$ of water.

The objective of this study was to develop a method for the determination of dissolved gases in a minimum volume of water, with a single shot and a good working range. The first part of this work focused on $\mathrm{CH}_{4}, \mathrm{CO}_{2}$ and $\mathrm{H}_{2} \mathrm{~S}$. Table 2 presents the analytical methods generally used for the analysis of each compound.

The only method existing for the simultaneous determination of $\mathrm{CH}_{4}, \mathrm{CO}_{2}$ and $\mathrm{H}_{2} \mathrm{~S}$ is the method of Childress et al. ${ }^{9}$ for the determination of high concentrations of these gases in blood. This procedure can be divided into three steps: extraction of the gases from water, separation and detection.

The purge and trap method seems to be the most efficient method for the extraction of $\mathrm{CH}_{4}, \mathrm{CO}_{2}$ and $\mathrm{H}_{2} \mathrm{~S}$, because of the enrichment step. However, several unsuccessful attempts were made by us to simultaneously cryotrap $\mathrm{CH}_{4}, \mathrm{CO}_{2}$ and $\mathrm{H}_{2} \mathrm{~S}$. The experiments were carried out using packed glass columns with different packing materials, the cryogen being liquid nitrogen. Childress et al. ${ }^{9}$ used an acid stripping method (dynamic headspace without trapping) in a purpose-built reactor; this method is only available for concentrated samples (blood) and small injection volumes.

An alternative method is headspace sampling which has a good working range for $\mathrm{CH}_{4}$ and $\mathrm{CO}_{2}$. This method was tested for the complete set of gases.

The complete chromatographic separation of $\mathrm{CH}_{4}, \mathrm{CO}_{2}$ and $\mathrm{H}_{2} \mathrm{~S}$ is not possible on a single column. A dual column system with a switching valve must be used. ${ }^{9}$ The first column used in the study of Childress was a Poraplot Q: this separated $\mathrm{O}_{2}, \mathrm{~N}_{2}$, $\mathrm{CO}$ and $\mathrm{CH}_{4}$ as a single peak from $\mathrm{CO}_{2}, \mathrm{H}_{2} \mathrm{~S}$ and water. The first peak $\left(\mathrm{O}_{2}, \mathrm{~N}_{2}, \mathrm{CO}, \mathrm{CH}_{4}\right)$ was trapped on the second column

Table 2 Analytical methods used in the literature

\begin{tabular}{|c|c|c|c|c|c|c|}
\hline Reference & Compounds & Matrix & Method & Detection & Calibration & Working range \\
\hline 1 & $\mathrm{CH}_{4}$ & Sea-water & Headspace & & & $3-700 \mu \mathrm{mol} 1^{-1}$ \\
\hline 2 & $\mathrm{CH}_{4}$ & Sea-water & Headspace & FID* & Gas standard & $5-20 \mathrm{nmol} \mathrm{l}^{-1}$ \\
\hline 3 & $\mathrm{CH}_{4}$ & Water & Headspace & $\mathrm{TCD}^{\dagger}, \mathrm{FID}^{*}$ & & $0.01-100 \mu \mathrm{mol} \mathrm{1}^{-1}$ \\
\hline 4 & $\mathrm{H}_{2}, \mathrm{CH}_{4}, \mathrm{CO}_{2}$ & Sea-water & Modified MHE & $\mathrm{TCD}^{+}$ & & $\mathrm{CH}_{4} 1-100 \mu \mathrm{mol} \mathrm{1}^{-1}$ \\
\hline 5 & Dissolved sulfides & Sea-water & Purge and trap & $\mathrm{PID}^{\S}$ & & DL $13 \mathrm{nmol} \mathrm{l}^{-1}$ I \\
\hline 6 & $\mathrm{CH}_{4}$ & Sea-water & Purge and trap & FID & Gas standard & $0.02-18 \mathrm{nmol} \mathrm{t}^{-1}$ \\
\hline 7 & $\mathrm{CH}_{4}, \mathrm{CO}_{2}$ & Sea-water & Purge and trap & $\mathrm{TCD}^{\dagger}, \mathrm{FID}^{*}$ & & \\
\hline 8 & $\mathrm{CH}_{4}$ & Sea-water & Ultrasonic & FID $^{*}$ & Gas standard & $0.05-45 \mathrm{nmol} \mathrm{I}^{-1}$ \\
\hline 9 & $\begin{array}{l}\mathrm{CH}_{4}, \mathrm{CO}_{2}, \mathrm{CO}, \\
\mathrm{H}_{2} \mathrm{~S}, \mathrm{~N}_{2}, \mathrm{O}_{2}\end{array}$ & Blood & $\begin{array}{l}\text { Dynamic } \\
\text { headspace }\end{array}$ & $\mathrm{TCD}^{\dagger}$ & Gas standard & $\begin{array}{l}\mathrm{CO}_{2} 4-20 \mathrm{mmol} \mathrm{l}^{-1} \\
\mathrm{H}_{2} \mathrm{~S} 0-5 \mathrm{mmol} \mathrm{l}^{-1}\end{array}$ \\
\hline
\end{tabular}

* FID, flame ionization detector. ${ }^{+}$TCD, thermal conductivity detector. $\ddagger$ MHE, multi-headspace extraction. $\$$ PID, photoionization detector. ${ }^{\circ}$ DL, detection limit. 
(molecular sieve), the valve was switched and $\mathrm{CO}_{2}, \mathrm{H}_{2} \mathrm{~S}$ and water were eluted directly to the detectors. When the elution was finished on the Poraplot column, the final separation of $\mathrm{O}_{2}$, $\mathrm{N}_{2}, \mathrm{CO}, \mathrm{CH}_{4}$ was carried out on the molecular sieve after a second valve switching.

Childress et al. ${ }^{9}$ used a thermal conductivity detector (TCD) for the detection of the gases. To improve sensitivity more specific detectors were used in this study: a TCD for $\mathrm{CO}_{2}, \mathrm{~N}_{2}$, $\mathrm{CO}, \mathrm{O}_{2}$, a flame ionization detector (FID) for $\mathrm{CH}_{4}$ and an FPD for $\mathrm{H}_{2} \mathrm{~S}$. Species were eluted to the different detectors using a second switching valve.

\section{Experimental}

A schematic diagram of the complete analytical device used is presented in Fig. 1.

A preliminary study was carried out using $20 \mathrm{ml}$ headspace flasks, with a $10 \mathrm{ml}$ sample of water and $0.1 \mathrm{ml}$ of $6 \mathrm{~mol}^{-1}$ hydrochloric acid under He. The flask was heated for $30 \mathrm{~min}$ at $70{ }^{\circ} \mathrm{C}$ under stirring. The injected headspace volume was 2.5 $\mathrm{ml}$. To reduce the analysis time, a temperature programme was used $\left[40^{\circ} \mathrm{C}\right.$ (held for $7 \mathrm{~min}$ ); raised at $15{ }^{\circ} \mathrm{C} \mathrm{min}-1$ to $130{ }^{\circ} \mathrm{C}$ (held for $13 \mathrm{~min}$ )].

The headspace sampler used was a DANI HSS 86-50 with a Silicostil heated transfer line. The separation was performed using a series 8000 Fisons gas chromatograph equipped with a TCD, an FID EL 980 and an FPD and LIN 700 (linearizer). The switching valves were made of Hastelloy (Valco). The columns and pressure drop were Chrompack Poraplot Q Ultimetal 0.53 $\mathrm{mm}, 25 \mathrm{~m}$ and Molecular sieve 5A Plot Ultimetal, fused silica $0.32 \mathrm{~mm}, 5 \mathrm{~m}$. The carrier gas was He N55 (0.49 bar). The integration software was Borwin 4 channels. Calibration was achieved either with a standard gas mixture from Scotty with Hamilton gas-tight syringes $1700 \mathrm{RN}$ series or with standard solutions of sodium sulfide nonahydrate (Rectapur, Prolabo) and sodium hydrogencarbonate (pro analysi, Merck).

\section{Results and Discussion}

Fig. 2 presents a chromatogram obtained with this method for concentrations of $35 \mu \mathrm{mol} \mathrm{l}^{-1}$ of $\mathrm{H}_{2} \mathrm{~S}, 200 \mu \mathrm{mol} \mathrm{l}^{-1}$ of $\mathrm{CO}_{2}$ and
$120 \mu \mathrm{mol} 1^{-1}$ of $\mathrm{CH}_{4}$. The valves were switched at $315 \mathrm{~s}(\mathrm{E} 1)$ $440 \mathrm{~s}$ (E2) and $14 \mathrm{~min}$ (E1, E2). The chromatographic resolution enabled quantitative analysis. However, the baseline for the TCD was disrupted by the temperature programme. The use of an isothermal temperature program or a mass flow controller would cancel this problem.

Fig. 3 presents the calibration curves for the three compounds, obtained by the liquid addition of $\mathrm{Na}_{2} \mathrm{~S}$ and $\mathrm{NaHCO}_{3}$ and gaseous addition of $\mathrm{CH}_{4}$ to $10 \mathrm{ml}$ of sea-water. The low sensitivity for $\mathrm{H}_{2} \mathrm{~S}$ may be due to the adsorption of sulfide on part of the gas chromatograph, although most of the inox parts had been replaced except for the syringe needle of the headspace.

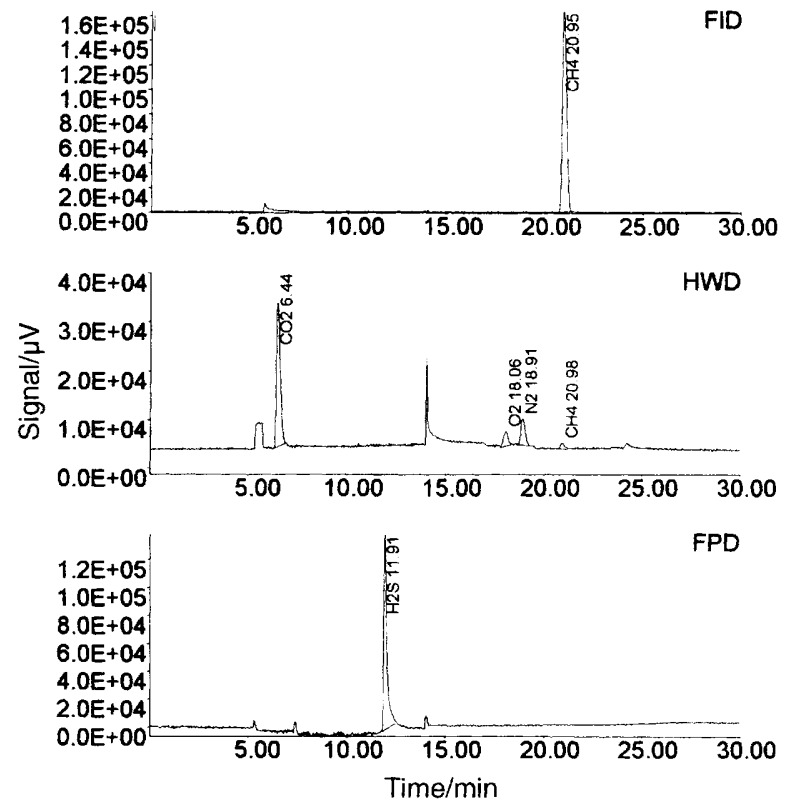

Fig. 2 Chromatogram obtained for a mixture of $\mathrm{Na}_{2} \mathrm{~S}\left(35 \mu \mathrm{mol} \mathrm{I}^{-1}\right), \mathrm{CO}_{2}$ $\left(200 \mu \mathrm{mol} \mathrm{l}^{-1}\right)$ and $\mathrm{CH}_{4}\left(120 \mu \mathrm{mol} \mathrm{l}^{-1}\right)$.

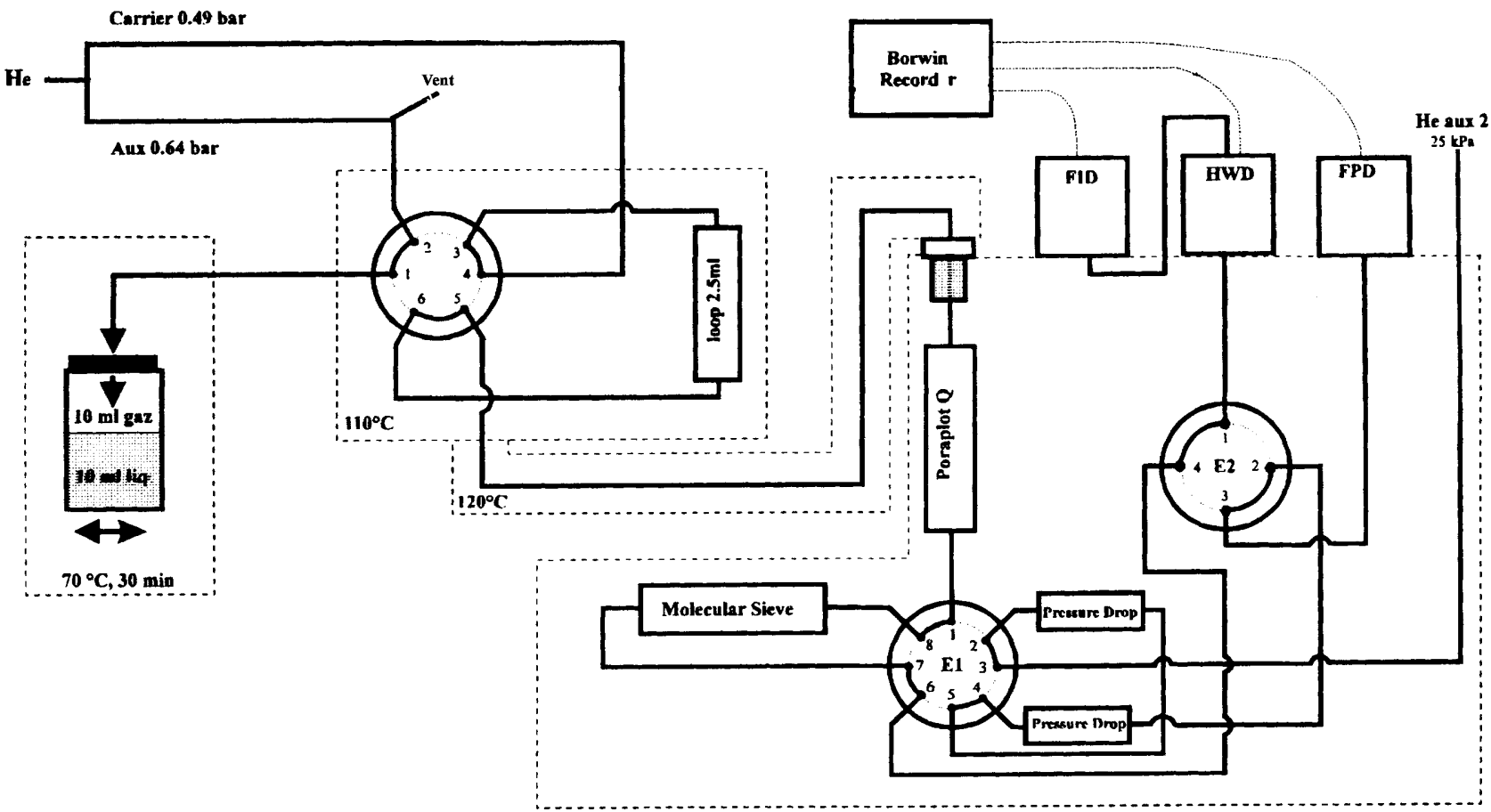

Fig. 1 Schematic diagram of the analytical device. 
The determination limits $(3 \times$ noise integration/calibration slope) were 0.1 and $50 \mu \mathrm{mol} \mathrm{I}^{-1}$ for $\mathrm{CH}_{4}$ and $\mathrm{CO}_{2}$, respectively. Standard deviations $(n=5)$ were $4 \%$ for $80 \mu \mathrm{mol} 1^{-1}$ of $\mathrm{CH}_{4}$ and $7 \%$ for $800 \mu \mathrm{mol} \mathrm{l}^{-1}$ of $\mathrm{CO}_{2}$.

\section{Application}

The analytical device described here has been used aboard the French oceanographic vessel 'Nadir' during the HOT 96 diving
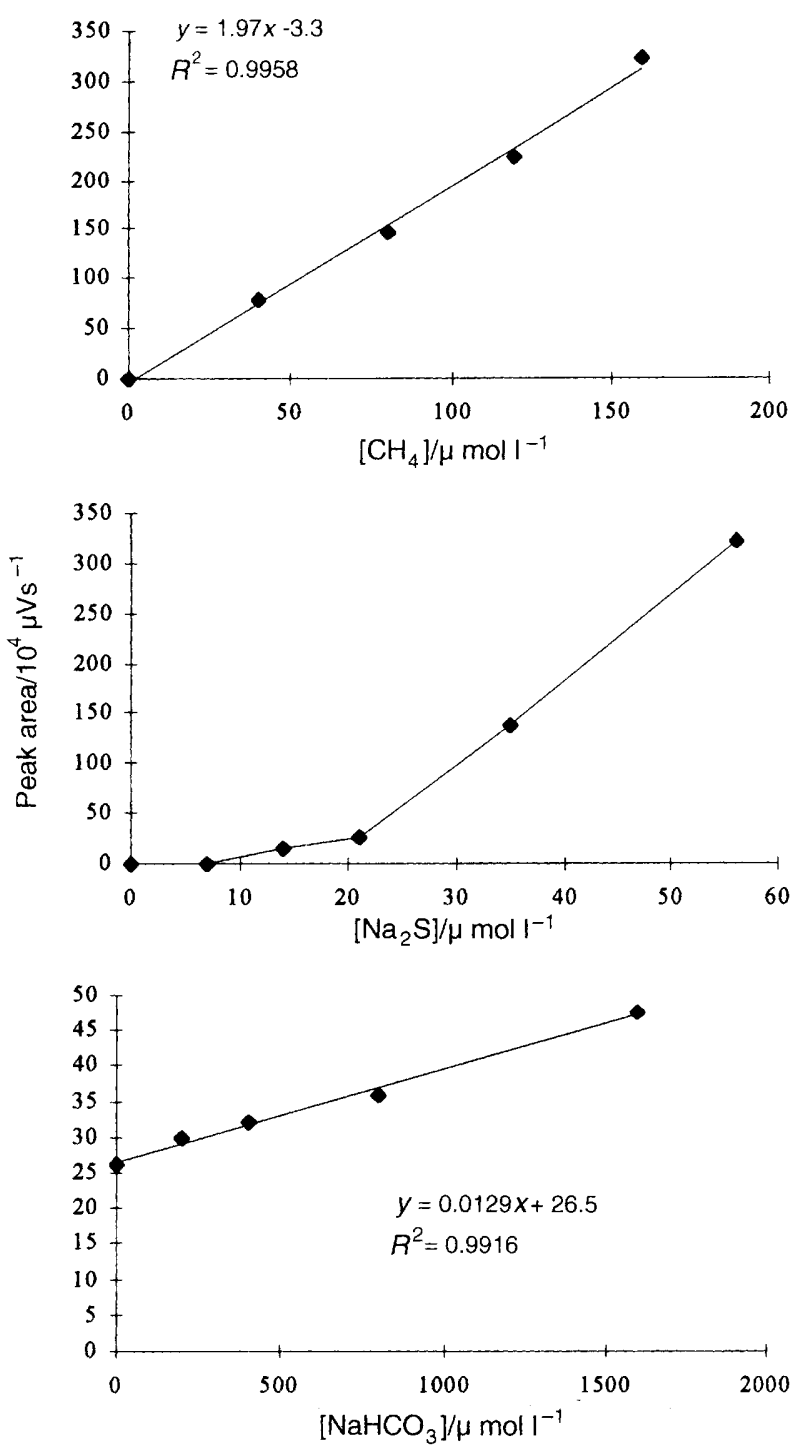

Fig. 3 Calibration curves for $\mathrm{CH}_{4}, \mathrm{H}_{2} \mathrm{~S}$ and $\mathrm{CO}_{2}$. cruise undertaken by IFREMER CNRS Marine Research Unit no. 7 on the $9^{\circ}$ and $13^{\circ} \mathrm{N}$ hydrothermal sites of the East Pacific Rise. Fifty water samples were collected of the various organisms present (Riftia, Alvinellids and mussels) by the French submersible Nautile using a specific vacuum-based and gas-tight sampler. Hydrogen sulfide was not quantified because of its low sensitivity. For methane and carbon dioxide concentrations of $1-5 \mu \mathrm{mol} 1^{-1}$ (sea-water $0 \mu \mathrm{mol} \mathrm{1^{-1 }}$ ) and

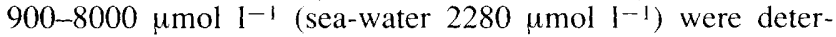
mined, respectively.

\section{Conclusions}

The headspace extraction conditions (temperature, time, pressure) must be further optimized to improve the efficiency and to reduce the amount of water injected. The hydrogen sulfide line must be checked to eliminate the possible remaining inox parts and to study the working conditions for the FPD (air and $\mathrm{H}_{2}$ amount in the flame) to enhance the sensitivity. The concomitant use of a TCD and a temperature program led to a fluctuating baseline use of a flow controller may overcome this problem.

This preliminary study has focused on the analysis of $\mathrm{CH}_{4}$, $\mathrm{H}_{2} \mathrm{~S}$ and $\mathrm{CO}_{2}$. Future work will involve the quantitative determination of $\mathrm{O}_{2}, \mathrm{~N}_{2}$ and $\mathrm{CO}$ using the same method.

This work was supported by a MAST III AMORES contract 950040 .

\section{References}

1 Blanc, G., Boulègue, J., and Gieskes, J. M., Occanol. Acta, 1991, 14, 33.

2 Bange, H. W., Bartell, U. H., Rapsomanikis, S., and Andrae, M. O., Global Biogeochem. Cvcles, 1994, 8, 465.

3 Hamilton, S. K., Sippel, S. J., and Melack, J. M., Biogeochemistry, 1995, 30, 115

4 Evans, W. C., White, L. D., and Rapp, J. B., J. Geophys. Res.. 1988, 93, 15.305 .

5 Cutter, G. A., and Oatts, T. J., Anal. Chem., 1987, 59, 717.

6 Charlou, J. L., and Donval, J. P., J. Geophys. Res., 1993, 98, 9625.

7 Ishibashi, J. I., Wakita, H., Nojiri, Y., Grimaud, D., Jean-Baptiste, P.. Gamo, T., Auzende, J. M., and Urabe, T., Earth Planet. Sci. Lett., 1994, 128, 183.

8 Schmitt, M., Faber, E., Botz, R., and Stoffers, P., Anal. Chem., 1991, 63, 529.

9 Childress, J. J., Lee, R. W., Saunders, N. K., Felbeck, H., Oros, D. R.. Toulmond, A., Desbruyères. D., Kennicutt, M. C., and Brooks. J.. Nature, 1993, 362, 147.

Paper 6/05335A

Received July 30, 1996 Accepted August 19, 1996 